\title{
Scientist and non-scientists share a diversity of dimensions in their relations to urban nature
}

\author{
Anne-Caroline Prévot ${ }^{1} \cdot$ Véronique Servais $^{2}$. \\ Armony Piron ${ }^{1}$
}

(C) Springer Science+Business Media New York 2016

\begin{abstract}
In the current biodiversity crisis, conservation scientists are urgently asked to involve themselves in education and communication initiatives toward non-scientists, who are considered as lacking knowledge to correctly value biodiversity. This is particularly argued in urban areas.

In this paper, we showed however with an anthropological survey that urban citizens do express a variety of relations toward surrounding urban nature. Then, in an independent survey, we showed that these ways of being connected with nature were shared by students in conservation sciences. Conservation scientists and non-scientific city dwellers have therefore much more in common than is taken for granted in their relations and perceptions of urban nature, notably concerning emotional, sensorial and memorial relationships. Acknowledging these common features in the scientific community could improve the communication between science and the general public about urban nature, help bridge the gap between science and the society and eventually participate to build a new social contract on nature.
\end{abstract}

Keywords Urban nature $\cdot$ Communication $\cdot$ Education $\cdot$ Conservation $\cdot$ Conservation psychology

\section{Introduction}

In the current biodiversity crisis, the involvement of people and society to implement conservation measures is now considered as one of the main targets of scientific and professional conservation

Anne-Caroline Prévot acpj@mnhn.fr

1 Centre d'Ecologie et des Sciences de la Conservation (CESCO UMR 7204), Sorbonne Universités, MNHN, CNRS, UPMC, Muséum national d'Histoire naturelle, CP 135, 61 rue Buffon, 75005 Paris, France

2 Laboratory of Social and Cultural Anthropology, Faculty of Human and Social Sciences, Quartier Agora, University of Liège, Place des Orateurs, B31, 4000 Liège, Belgium 
communities (e.g., Novacek 2008). Consequently, it appears to be particularly efficient to work in cities, where most people now live and work (United-Nations 2011). However, in these areas, the elements of nature with which citizens are in contact are progressively changing towards fewer, less diverse and more domesticated biodiversity (see Pickett et al. 2001). In this context, R. Pyle (2003) and J. Miller (2005) proposed the hypothesis of an extinction of experience, formulated as follows (Pyle 2003: 209): "When common species of plants and animals (as well as cultural, architectural, or any other features of diversity) become extirpated in one's everyday environs within, that is, one's radius of reach - one grows increasingly inured to their absence (The radius of reach is smaller for the poor, the very old, the very young, and the disabled.) That is, richness of the neighborhood diminishes, the power of the neighborhood to fascinate, arouse, excite, and stimulate also passes into dullness, ennui, and apathy. Those who know and recognize less, care less, and therefore act less, leading to still more losses. (...) So the extinction of experience precipitates a cycle of disaffection, degradation, and ultimate separation from nature".

Formal education initiatives are encouraged (Lindemann-Matthies 2006; Shwartz et al. 2012), in order to make urban citizens more concerned with biodiversity and conservation issues (Brewer 2001). Here, biodiversity is defined as a dynamic diversity of living organisms in interactions with each other (Begon et al. 2006); the nature considered by the scientific community refers to biodiversity defined in this way. Based on this definition, a recent study suggested a decreasingly biodiversity-related vision of nature in a specific category of lay people, animated film-maker teams (Prévot-Julliard et al. 2015). Most education initiatives are therefore based on the conception that "when people understand and appreciate the value of biodiversity, they will be more likely to think about conservation when they vote, make purchases, or decide about uses of land and natural resources" (Noss et al. 2012, p. 3). This assertion presupposes the existence of a single and objective vision of the "value of biodiversity", shared by "conservation professionals of all varieties", who "should invest more effort in explaining and marketing biodiversity conservation in compelling ways", for instance education, so that their vision of the value of biodiversity could be shared by lay people as well. However the non-human nature encountered in everyday lives mostly does not refer to the scientific definition of biodiversity (Cooper 2000). Biodiversity may be considered as neologism designed to stress the current crisis (Maris 2012) based on the scientific vision; by contrast, the term "nature" refers to all personal experiences of the natural world, such as sensitive, emotional, or symbolic experiences (e.g., Kahn et al. 2010). By considering nature only through the filter of biodiversity, the normative value of biodiversity, as assessed by the conservation community, implies a dichotomy between accurate and inaccurate relations to nature, the vision considered as relevant and correct being the one shared and expressed by the scientific community, and not by the vast majority of lay people (e.g, Buijs et al. 2011).

Yet, several studies on education have already challenged this simple conception: regarding climate change, recent researches suggest that transmission of scientific knowledge does not successfully overcome ideological divides (Zia and Todd 2010). Similar results have been found with regard to environmental attitudes: correlation is not automatic between people's environmental educational level and their environmental attitudes (e.g., Ewert et al. 2005).

Although less diverse than in other areas, nature is present in cities (Dunn et al. 2006). And nature is an object, par excellence, with which everyone has developed individual relations, from his/her youngest age (Kahn and Kellert 2002). Diverse relations with surrounding nature are therefore likely to exist in urban citizens. However, how much these relations to urban-nature differ between lay people and conservation experts remains poorly studied (Buijs and Elands 2013). 
In the current study, we explored this gap in an original inductive method including two successive steps. We chose this methodology to provide the largest set of relations to urban nature among city dwellers to emerge, without any predefined hypotheses. To do that, we explored with an anthropological survey the dimensions of the relations that city-dwellers develop toward their surrounding urban nature in a highly urbanized context. As a result, we proposed a typology of six complementary dimensions of individual relations to urban nature, which are mobilized alone or together depending on the contexts. Secondly, we used this typology to analyse the relations to urban nature among students in ecology and conservation science. These students are going to become experts in ecology or conservation, and will eventually work in conservation sciences, landscape management, or environmental education. We showed that these students share the six dimensions detected in urban citizens.

We discuss our results in the light of theories coming from conservation psychology, and we suggest that the scientific community could be more efficient in its education program if it took all these dimensions into account.

\section{Methods}

\section{Anthropological survey}

We conducted an anthropological survey of individual relations to nature (more precisely with elements of nature: an animal, a tree, a plant, an animal species, an urban park...) in the SeineSaint-Denis, a highly urbanized area in the north-east surroundings of Paris (France). In this area, urban nature in public areas is mainly located in small to large green spaces, managed through municipal or institutional departmental public policies. At this level, public policies have led to an increase in the offer of green space, from less than 1 ha per inhabitant to more than 12 ha in less than 15 years. In addition, urban citizens in this area represent a high variability of cultures and socio-economic statuses (Anonymous 2012).

We conducted the anthropological survey by a methodology based on long semi-structured and place-based interviews (Kaufmann 1996), which aim to help the interviewee to follow a deep personal thought process. All the interviews have been conducted by the same interviewer (A.P.). The interviewer formulated a list of questions prior to the interview, but these questions were never explicitly asked during the interview. On the contrary, the interviewer behaved like an intellectual artist, and adapted her own behaviour and attitudes to the respondent, without expressing any particular opinion or, more importantly, any knowledge. In order to take into account the importance of physical place where the interview is conducted in the thinking and the discourses of the respondents, interviews of a single person were asked to be carried out in different places: at home, in the park where the person used to go (if any), and outside the house, in the neighbourhood (Table 1).

During the year 2009, 29 different people (14 men and 15 women) between twenty and more than sixty years of age have been interviewed (Table 1). These people were all living in the Seine-Saint-Denis area; they were from different socio-professional categories and education level. 13 out of them were interviewed only in their home, 4 in two different outside areas but not at home, 5 at home and in one public space, and 7 at home and in two different public spaces. Only thirteen people (out of 29) have been recruited directly in the public space. Indeed, it appeared very difficult to recruit people this way, because most people solicited for 
Table 1 Individual characteristics of the 29 interviewed city dwellers. Interviewed people were contacted directly (direct) in public spaces or using the snowball technique (Indirect). They were interviewed in up to 3 different places: their home, their preferred public greenspace and their neighbourhood

\begin{tabular}{|c|c|c|c|c|c|}
\hline Family status & Gender & Age & home type & Contact & Places of interview \\
\hline Single & Woman & $50-59$ & Apartment & Direct & 3 (home/greenspace/neighborhood) \\
\hline Paired & Man & $60+$ & House & Direct & 2 (greenspace/neighborhood) \\
\hline Single, children & Man & $31-39$ & Apartment & Direct & 3 (home/greenspace/neighborhood) \\
\hline Single & Man & $20-29$ & Apartment & Direct & 2 (greenspace/neighborhood) \\
\hline Paired & Man & $20-29$ & House & Indirect & 1 (home) \\
\hline Paired & Woman & $20-29$ & House & Direct & 2 (home/greenspace) \\
\hline Paired & Woman & $50-59$ & Apartment & Direct & 1 (home) \\
\hline Paired, children & Woman & $40-49$ & House & Indirect & 1 (home) \\
\hline Single, children & Woman & $60+$ & Apartment & Indirect & 3 (home/greenspace/neighborhood) \\
\hline Paired, children & Woman & $30-39$ & House & Indirect & 1 (home) \\
\hline Paired, children & Woman & $30-39$ & Apartment & Indirect & 2 (home/greenspace) \\
\hline Paired, children & Man & $30-39$ & Apartment & Indirect & 3 (home/greenspace/neighborhood) \\
\hline Single & Woman & $40-49$ & Apartment & Direct & 3 (home/greenspace/neighborhood) \\
\hline Paired, children & Woman & $30-39$ & Apartment & Indirect & 1 (home) \\
\hline Paired, children & Woman & $60+$ & House & Indirect & 1 (home) \\
\hline Paired, children & Man & $60+$ & House & Indirect & 1 (home) \\
\hline Paired, children & Woman & $60+$ & House & Indirect & 1 (home) \\
\hline Single & Man & $20-29$ & House & Indirect & 3 (home/greenspace/neighborhood) \\
\hline Paired, children & Woman & $20-29$ & Apartment & Direct & 2 (home/greenspace) \\
\hline Paired, children & Man & $30-39$ & Apartment & Direct & 3 (home/greenspace/neighborhood) \\
\hline Paired & Woman & $50-59$ & Apartment & Direct & 2 (home/neighborhood) \\
\hline NA & Woman & $60+$ & Apartment & Indirect & 1 (home) \\
\hline Single & Man & $20-29$ & Apartment & Indirect & 2 (home/greenspace) \\
\hline Single & Man & $30-39$ & Apartment & Indirect & 2 (greenspace/neighborhood) \\
\hline NA & Man & $20-29$ & Apartment & Direct & 1 (home) \\
\hline Single & Man & $40-49$ & House & Direct & 2 (greenspace/neighborhood) \\
\hline Paired & Woman & $20-29$ & Flat & Direct & 1 (home) \\
\hline Paired & Man & $20-29$ & Flat & Indirect & 1 (home) \\
\hline Single & Man & $20-29$ & Flat & Indirect & 1 (home) \\
\hline
\end{tabular}

an interview about nature around them answered that there was no nature in their surroundings. Therefore, 16 more people have been recruited using the snowball sampling technique (Biernacki and Waldorf 1981). Approximate duration of interviews was 4-6 h. All the interviews were done in French, i.e. native language of the interviewer.

All the interviews were then transcribed and analysed. The analysis was mostly qualitative: responses were gradually gathered in groups according to their theme and to what people were telling about their relationship with nature. When an observation or a statement could not be attributed to one previously defined dimension, a new one was created. It was gradually refined by analysis of the remaining data and we ended up with a typology of six naturerelation dimensions. With 29 people, we achieved data saturation, i.e. no new data nor dimension was found by the last respondents. 
During the interviews, the term "biodiversity" was never used. Instead, the interviewer used the term "nature" without defining it. This was meant to let the respondents as free as possible regarding their own definition of nature. The various meanings given by the respondents are presented in the results of the study.

\section{Conservation students' survey}

During the academic year 2013-2014, the relations that students in ecology and conservation sciences develop with nature were assessed through a picture-based questionnaire survey. As for the anthropological survey, no a priori typology was exposed to the students before the exercise, and we similarly offered no definition of the term "nature". On the contrary, during a specific sequence within a course on conservation science, A.C.P. showed students 12 photographs of common animals present in a specific green space close to a small river (Table 2). Each picture was then presented during $30 \mathrm{~s}$. The pictures were specified only by a number without any name on them, and were presented as "animals that one can see in an urban green space close to a river". Then, students were asked to write the "first three words or expressions that come to their mind when they see the pictures". This methodology is derived from the free-listing methodology (Abric 1994) or the word association methodology (Haartsen et al. 2003, cited in Buijs and Elands 2013) implemented to elicit social representations. This theory (Moscovici 2000) proposes that people of a given social group share common representations of a given object (here, natural elements such as common animals), which can be explicated by asking people to say whatever they think about the studied object or concept, without the constraint of pre-defined categories.

This test concerned 67 students from 4 different teaching classes (Licence in urban green management, master in ecology (year 1 and 2) and master in geography and conservation).

We collected the words written by each student and we conducted grammatical and synonymous homogenization, to get a total of 666 words and 2322 occurrences. We then asked 5 colleagues (who were not involved in the first part of the study) to independently

Table 2 Animal species (Latin names in brackets) presented to conservation students in order to assess their relations to nature

\begin{tabular}{lll}
\hline Number & Animal species & Conservation status in France \\
\hline 1 & Mallard duck (Anas platyrhynchos) & Wild and hunted species \\
2 & Coypu (Myocastor coypus) & Introduced species \\
3 & Common moorhen (Gallinula chloropus) & Wild and shy species \\
4 & Common pipistrelle (Pipistrellus pipistrellus) & Nocturnal species \\
5 & Great heron (Ardea cinerea) & Wild species \\
6 & European Frog (Pelophylax kl. Esculentus) & Wild species \\
7 & Wasp spider (Argiope bruennichi) & Wild species \\
8 & Greylag goose (Anser anser) & Domestic species \\
9 & European Robin (Erithacus rubecula) & Wild species \\
10 & Red squirrel (Sciurus vulgaris) & Wild species \\
11 & Domestic horse & Domestic species \\
12 & Rose-ringed parakeet (Psittacula krameri) & Introduced species \\
\hline
\end{tabular}


classify the 108 words with more than 5 occurrences based on our pre-defined typology. We tested the reliability of their classification with Fleiss'Kappa (Fleiss 1981, cited in Buijs and Elands 2013).

\section{Results}

\section{A typology of 6 nature-relation dimensions}

As it has been stated before, we did not give any indication about what was to be considered as nature to our informants. Accordingly, we decided to accept as nature any element considered as such by the interviewees. We ended up with a very large definition of nature as every living animal or plant, including domesticated animals, cultivated plants and even fruits or vegetables found in shops.

Following the thematic classification described above, six different dimensions were found that structure any relation to nature - or, more precisely, to elements of nature: individuals (a pet, a given tree in a park), a species (rabbits in a park, cultivated vegetables on a balcony) or a landscape (a park, a street with trees...).

To prevent any hierarchy, we present these dimensions in an alphabetical order.

Affective dimension This dimension is used when an individual perceives instinctively a natural element as pleasant or unpleasant (quotes 1a and $1 \mathrm{~b}$ ).

Quote 1.a [in a small urban farm, looking at dwarf domestic goats]

Oh, look, it comes!!! Oh!!! It's wonderful, we should come more often! (...) It's crazy, they are not afraid! It's wonderful, I love it!!!

Quote 1.b [concerning rats]

I never saw any. Honestly, I'm very happy. Honestly, I think I'd become hysterical! I do not like them at all. No, no, no, no rat, no mouse, or I'll have a heart attack. I don't like them at all!

This emotive perception relies on the autonomic nervous system (Ekman et al. 1983; Kreibig 2010), even if it can be modulated by cognitive factors (e.g., Sezille et al. 2014). Some respondents for instance rationalized their relations to the natural element they were afraid of (quote 2), firstly by describing them.

Quote 2

I'm afraid of rats!!! So, I'm afraid of rats. Actually, we had some, before, they were cute but I didn't force myself because I was afraid. And indeed, by visiting web forums, where they put some pictures of their rats, and sometimes not only pictures but stories, I read them (...) I convinced myself to become an accepting family. But it was horrible, I forced myself. I trembled and so on! (...) It's strange, I forced myself not to be afraid. I really wanted to fight my fear.

Analogical dimension This dimension relies on the implicit comparison with the human body, mind or societies to describe and understand nature. This is not simply anthropomorphism, but instead drawing analogies between human beings and other natural beings in order 
to relate to them. For example, sap is to the tree what blood is to animals. It is always difficult to evaluate how much of the analogy is taken seriously. For some people, animals' (and sometimes plants') behaviour and emotions are like human ones (quote 3):

Quote 3 [in front of a cut plant]

Of course I hurt her, what do you think? That I'm not aware of that? She has flowing sap, it's like blood, but she has already healed here, and here.

Memorial dimension When using this dimension, natural elements are not considered for themselves, but as recollections of people or events. They often refer to individual childhood (quotes 4 and 5). We were surprised by the great amount of memories that the conscious perception of natural elements can bring. It seems that nature connect people to their own past.

Quote 4

To go to the subway, it's obvious for me to walk through the park, for pleasure. It's important. For sure, I would not walk on the boulevard, which is nice, one sees the park and the trees; no, I like to walk through the park.

- What kind of pleasure do you feel, could you explain?

- I'd say, maybe some childhood memory. Because when we were young, we used to go to these parks.

Quote 5

I planted a honeysuckle and a bay, which I can see out the window, because when I was a child, I used to see some out the window.

Natural elements can also refer to social relations, with close people. For instance, one respondent declared no willingness to be in nature: she does not have any plant in her apartment, nor a pet; she does not go to urban parks and declared that she "is bored in nature". However, when the interviewer entered her apartment, she discovered a very nice bouquet of flowers. When being asked, the respondent explained that this bouquet was a present from her daughter and that she takes care of it to make it last as long as possible. Indeed, she explained that every time she takes care of this bouquet, she is reminded of her daughter. The bouquet was somehow a part of her daughter.

Objective dimension This dimension is used when describing nature with rational arguments and objective scientific vision (quote 6). The emotions are left apart, to concentrate on an external point of view. Intellectual actions such as naming or classifying plant and animal species proceed to this dimension.

Quote 6 [about organized field trips in urban environments].

To know that this bird is a blackbird, it does not go so far! But to know that the cuckoo, for instance, when it lays eggs, it will lay them in the nest of another bird variety, that it will get rid of the eggs of this bird variety, this, is very interesting! Yes! But to know that its name is cuckoo, it's not important.

Sensorial dimension Contrary to objective rational dimension, the sensorial dimension of individual relation to nature is effective when an individual experiences his/her relation with 
nature mainly as a sensorial experience, with one or several of the five senses (seeing, hearing, touching, smelling, tasting, quote 7).

Quote 7

Now, I'm going to hear the wind, I will let it go [freezes, extends his arms and legs, and breathes], and I'm going to hear it. I do this and I immerse myself... It's something... difficult to explain.

Utilitarian dimension This relation mode is mobilized when using nature to increase our own personal well-being, that includes five components (MEA 2005): essential human needs (e.g. food), health (including healthy environment, air and water), social relations (e.g., social cohesion, child caring), security and individual freedom.

Among respondents, individual actions such as eating, drinking, washing or heating were not recognized as particularly related to urban nature. However, so-called "cultural services" (MEA definition) were cited by different people (quotes 8 and 9): meeting places for social activities, resting places, sporting places

Quote 8:

I don't deny the importance of the park: it is a vital area that allows one to make a contrast with the city. I feel this is very very important. (...) Many people go to the parks to make barbecues, that is to meet in the city, to find convenient places to meet, to discuss with others without traffic noise. So, for that, I think they are useful.

Quote 9:

When I go to Boulogne woods or Vincennes woods [the two largest urban parks in Paris], I really feel I have left Paris, I have really this feeling. And even with friends, when we go there to picnic, it's very pleasant, this aspect: there are games for children, to play, with sandboxes; there are also large pretty and managed lawns, there are also many guards.

\section{Six fluid and context dependent nature-relation dimensions}

For the clarity of our argument, we described all these nature-relation dimensions separately. However, these dimensions are not so separated from each other; they can even be invoked together, in a complementary way (quotes 10 and 11).

Quote 10 [the respondent referred to a recent outdoor bird education program he participated in; he referred to objective, affective, utilitarian]:

I feel that I communicate more with nature (...) because you have relations to nature at that time. You can give a name. Yes, yes, yes. You discover really, you put a name on it. (...) It is gradually that you maintain it, that you increase it. (...) It is a state of fullness. It is not worth describing it or anything! You feel better. You really communicate with something you did not know before. (...) Now, I realize that when I walk in the forest, I say "hey, it could be this bird" whereas before, I thought "this is pretty, it's nice", but nothing more! While now, I even can put a name on a song. (...) So, the outdoor trips allow you to get the keys to discover later on, to be a man inside nature. It gives you keys but. .. afterwards, it is up to you to use these keys. 
Quote 11 [objective, sensorial, even memorial]

In scientific education, you are always trained to refer to what you see, interactions between species. But I never learned - maybe there are people that do that - what you feel toward these species, and what these species give back to us when we observe them. (...) Many people refer only to taxonomic characteristics to describe a plant, i.e. "there is this or this diagnostic character; we recognize it, ok, that's it". For me, I refer to the feeling I have when I look at the plant (...) It's not that it's forbidden, but we are not made to think about it that way; we don't talk about it. In scientific education at university, teachers say "fruits are like that, flowers are like that", and never "remember your feelings, which smells, which sounds".

\section{Nature-relations of conservation students}

According to five independent ratings, the 108 most cited words that conservation students associated with common animals covered all the six dimensions found in the interviews of city-dwellers.

The five ratings were only fair in agreement (Fleiss' Kappa $=0.246$ ), suggesting that a single word is not clearly identifiable to a single category. However, each ranker used all the six classes to assess these 108 words (Table 3), suggesting that conservation students mobilize similar dimensions than lay people in their relations to nature, even in the formal context of class-room and towards vicarious elements of nature.

\section{Discussion}

Our study revealed the co-existence of several dimensions in the relationships that people develop with their natural surroundings in a highly urbanized context. The six dimensions we accounted for in this study refer to relations people really experience with the natural elements they are in contact with. Our results thus mostly refer to individual attitudes (i.e., "evaluative beliefs about a specific object", Koger and Winter 2010, p. 112) and behaviour towards what they call nature. Because all interviews had to be conducted in French, most of the interviewees were actually speaking French and were born or living in France for a long time. We

Table 3 Distribution of the different dimensions of the relation to nature assessed by 5 independent rankers

\begin{tabular}{lllllll}
\hline Dimension & $\begin{array}{l}\text { Ranker } \\
1\end{array}$ & $\begin{array}{l}\text { Ranker } \\
2\end{array}$ & $\begin{array}{l}\text { Ranker } \\
3\end{array}$ & $\begin{array}{l}\text { Ranker } \\
4\end{array}$ & $\begin{array}{l}\text { Ranker } \\
5\end{array}$ & Total \\
\hline Analogical & 4 & 7 & 6 & 13 & 12 & 42 \\
Emotional & 16 & 21 & 14 & 10 & 5 & 66 \\
Memorial & 9 & 1 & 11 & 6 & 14 & 41 \\
Objective & 27 & 14 & 39 & 34 & 56 & 170 \\
Sensorial & 15 & 37 & 25 & 16 & 9 & 102 \\
Utilitarian & 24 & 21 & 13 & 14 & 12 & 84 \\
Other & 13 & 7 & 0 & 15 & 0 & 35 \\
\hline
\end{tabular}


cannot therefore discuss any difference or similarities between cultures concerning these relations. However, even within a group of somehow acculturated people, we identified an important diversity of relationships to urban nature. In the student survey, the collected data could have been used to study in more details individual and collective representations of nature. However, we showed that these representations are consistent with the elicited dimensions of individual relationships to nature along city-dwellers.

In this study, we used an anthropological survey without any pre-defined hypothesis or classification, based on semi-directive open interviews, with a very open interview guideline and with no questionnaire or precise questions. However, the dimensions that we found are consistent with already published work. For instance, the objective and analogical dimensions of this study are consistent with Clayton and Myers (2009) cognitive component of individual attitude to nature, as well as with Kellert's (2002) naturalistic or scientific values of nature. The affective dimension of this study is very close to the biophilia hypotheses developed by Kellert and Wilson (1993). The affective and sensorial dimensions of this study are consistent to Clayton and Myers (2009) affective component of individual attitudes to nature, as well as with Kellert's (2002) humanistic, aesthetic and negativistic values of nature. The utilitarian dimension is consistent with Kellert's (2002) utilitarian value of nature. Finally, the memorial dimension takes an original place within the already published results, as it considers the natural element as a mediator for social relations (but see Root-Bernstein 2014). However, Freeman et al. (2012) found such a relation, in their so-called "connection to nature": "Plants were spoken of as holding historic memories. Plants taken from parents' gardens, plants as gifts on retirement, plants to commemorate loved ones..." (p. 141).

The relevance of any these six dimensions to biodiversity conservation is variable (see also Buijs and Elands 2013). Regarding this issue, the analogical relation to nature is of particular note. Indeed, one of the most frequent values in conservation biology is the recognition of the importance of nature's evolutionary and ecological dynamics (Soule 1985), regardless humans. Therefore, in its extreme expression, the analogical relation to nature, in denying the otherness of nature but considering its functioning as being equivalent to human functioning, could become incompatible with any achievement of a conservation-friendly way of life. However, having a moderate analogical relation to nature may be a way to connect with it. All the other dimensions of relation to nature could be associated with a conservation-friendly individual way of life. And indeed, all these dimensions were found in the representations of the conservation students questioned in the second part of the study.

Even though we did not collect quantitative data to directly compare the two studied cohorts, we nevertheless observed that city-dwellers more rarely expressed the objective dimension of relations to nature than other dimensions. On the contrary, this dimension was the most prominent among conservation students. Indeed, the objective relation to nature is generalized among western scientists and conservationists, who share the common western naturalistic vision of nature (Thomas 1983; Descola and Pälsson 1996) and the dominant Western paradigm of separation between humans and nature (Koger and Winter 2010). This objective relation to nature is mostly encouraged in environmental education programs. The Western vision of education still tends to consider the idea of educating the emotions as a "taboo subject" (Maxwell and Reichenbach 2005). Pupils are trained to exclude emotions from their understanding of the surrounding world, based on the fact that emotions are inaccurate for scientific purposes and rational decisions (“Descartes error”, Damasio 1995). 
However, intellectual relation to nature has been proved not to be the only way to take decisions regarding biodiversity and conservation (e.g., Bamberg and Möser 2007). In addition, the observed lack of direct causal relationships between objective knowledge acquisition and individual attitudes has psychological foundations based on the cognitive dissonance theory (Festinger 1957). This theory suggests that it is emotionally disturbing and, hence, unpleasant to hold inconsistent attitudes or behaviours. The will to be self-consistent is so important for individual psychological wellbeing that everyone is prone to reject external knowledge or facts as soon as they endanger his or her own previously built rationalization (Pigliucci 2012). As soon as the objective training of relationships to nature comes in conflict with individual previous assessments (through emotions or analogies), this novel knowledge is likely to be excluded from the existing rationalization of individuals.

For all these reasons, to rely exclusively on objective scientific education to increase individual awareness and concern for biodiversity conservation appears inadequate to us (see also Snep et al. 2015). And indeed, our results open another direction. As we confirmed that different nature-relation dimensions coexist in a single non-scientist individual, we also showed that this is true for people engaged in conservation issues. Our results are consistent with several independent studies on related subjects: Buijs and Elands (2013) showed with a questionnaire survey addressed to lay people and conservationists that both share the same relations to nature (that the authors referred as normative, descriptive and affective), although not in the same proportions; Chawla (1999) showed that environmental activists referred first to memorial relations to nature to explain their involvement; a recent survey in the French community of conservation biologists, confirmed that every respondent referred to a specific non-scientific experience that let him work in conservation (Clavel 2012), but without expressing this relation to official discourses (see also Sezille et al. 2014). Cooper (2000) reminds us that famous naturalists and ecologists were empathetic with natural elements.

Different frameworks already exist to help scientists and other stakeholders integrate different sorts of knowledge in a common decision-making process (e.g., Failing et al. 2007; Raymond et al. 2010). Daugstad (2008) showed that even with different attitudes toward rural landscape, different stakeholders could unite in specific focuses. In the cities, Lee et al. (2008) showed that neighbourhood satisfaction of inhabitants was correlated with landscape structures and could fit with ecological objectives of nature in cities. These examples show that successful communication is possible between scientists, experts and lay people. However, in Europe, most nature protection and biodiversity management still rely on scientific knowledge (Siebert et al. 2008).

\section{Conclusion}

In this study, we showed that scientists and non-scientists share a diversity of relations to urban nature. If urban ecologists accept that they develop relations to nature beyond the purely objective (including also affective, utilitarian and memorial), they could identify some common features with city dwellers; that could help bridge the existing gap between science and society concerning nature (Meinard and Quétier 2014). We therefore call scientists to acknowledge that they share common dimensions in their relations to nature with city dwellers, whom respective importance varies between individuals and depends on the context. Then, a new framework for communication and education on urban nature could be performed, which could also help build a new social contract on nature. 
Acknowledgments The authors thank the ODBU (Observatoire Départemental de la Biodiversité Urbaine) and Catherine Maurisson for their support, as well as M. Root-Bernstein for English editing. A. Piron was funded by the Department of Seine-Saint-Denis, through a pluri-annual partnership collaboration with the French National Museum of Natural History.

\section{References}

Abric JC (ed) (1994) Méthodologie de recueil des représentations sociales, Pratiques sociales et représentations. Presses Universitaires de France, Paris

Anonymous (2012) Les dynamiques sociales en Seine-Saint-Denis (1999-2010). Service de l'Observatoire Départemental de Seine-Saint Denis, Bobigny, France.

Bamberg S, Möser G (2007) Twenty years after Hines, Hungerford, and Tomera: a new meta-analysis of psychosocial determinants of pro-environmental behaviour. J Environ Psychol 27:14-25

Begon M, Townsend CR, Harper JL (2006) Ecology: from individuals to ecosystems. John Wiley \& Sons, Malden, MA

Biernacki P, Waldorf D (1981) Snowball sampling: problems and techniques of chain referral sampling. Sociol Methods Res 10:141-163

Brewer C (2001) Cultivating conservation literacy: "trickle-down" education is not enough. Conserv Biol 15: 1203-1205

Buijs AE, Elands BHM (2013) Does expertise matter? An in-depth understanding of people's structure of thoughts on nature and its management implications. Biol Conserv 168:184-191

Buijs AE, Arts BJM, Elands BHM, Lengkeek J (2011) Beyond environmental frames: the social representation and cultural resonance of nature in conflicts over a Dutch woodland. Geoforum 42:329-341

Chawla L (1999) Life paths into effective environmental action. J Environ Educ 31:15-26

Clavel J (2012) Biodiversité et écologues. In: Fleury C, Prévot-Julliard AC (eds) L'exigence de la réconciliation. Biodiversité et société. Fayard and Muséum, Paris, pp. 211-224

Clayton S, Myers G (2009) Conservation psychology. Understanding and promoting human care for nature, Wiley-Blackwell

Cooper NS (2000) Speaking and listening to nature: ethics within ecology. Biodivers Conserv 9:1009-1027

Damasio AR (1995) L'erreur de Descartes: la raison des émotions. Odile Jacob, Paris

Daugstad K (2008) Negotiating landscape in rural tourism. Ann Tour Res 35:402-426

Descola P, Pälsson G (1996) Nature and society: anthropological perspectives. Routledge, London

Dunn RR, Gavin MC, Sanchez MC, Solomon JN (2006) The pigeon paradox: dependence of global conservation on urban nature. Conserv Biol 20:1814-1816

Ekman P, Levenson RW, Friesen WV (1983) Autonomic nervous-system activity distinguishes among emotions. Science 221:1208-1210

Ewert A, Place G, Sibthorp J (2005) Early-life outdoor experiences and an individual's environmental attitudes. Leis Sci 27:225-239

Failing L, Gregory R, Harstone M (2007) Integrating science and local knowledge in environmental risk management: a decision-focused approach. Ecol Econ 64:47-60

Festinger L (1957) A theory of cognitive dissonance. Row Peterson, Evanston

Fleiss JL (1981) Statistical methods for rates and proportions. John Wiley, New-York

Freeman C, Dickinson KJM, Porter S, van Heezik Y (2012) "my garden is an expression of me": exploring householder's relationships with their gardens. J Environ Psychol 32:135-143

Haartsen T, Groote P, Huigen PPP (2003) Measuring age differentials in representations of rurality in The Netherlands. J Rural Stud 19:245-52

Kahn PH, Kellert SR (2002) Children and nature: psychological, sociocultural, and evolutionary investigations. MIT Press, Cambridge, MA

Kahn PH Jr, Ruckert JH, Severson RL, Reichert AL, Fowler E (2010) A nature language: an agenda to catalog, save, and recover patterns of human-nature interaction. Ecopsychology 2:59-66

Kaufmann JC (1996) L'entretien compréhensif. Armand Colin, Paris

Kellert SR (2002) Experiencing nature: affective, cognitive, and evaluative development in children. In: Kahn PH, Kellert SR (eds) Children and Nature. pp 117-151

Kellert SR, Wilson EO (1993) The biophilia hypothesis. Island Press, Washington D.C

Koger SM, Winter DDN (2010) The psychology of environmental problems -, 3rd edn. Taylor \& Francis Group, New York

Kreibig S (2010) Autonomic nervous system activity in emotion: a review. Biol Psychol 84:394-421 
Lee SW, Ellis CD, Kweon BS, Hong SK (2008) Relationship between landscape structure and neighborhood satisfaction in urbanized areas. Landsc Urban Plan 85:60-70

Lindemann-Matthies P (2006) Investigating nature on the way to school: responses to an educational programme by teachers and their pupils. Int J Sci Educ 28:895-918

Maris V (2012) Philosophie de la biodiversité. Petite éthique pour Une nature en péril. Buchet-Chastel, Paris

Maxwell B, Reichenbach R (2005) Imitation, imagination and re-appraisal: educating the moral emotions. J Moral Educ 34:291-307

Meinard Y, Quétier F (2014) Experiencing biodiversity as a bridge over the science-society communication gap. Conserv Biol 28:705-712

Miller JR (2005) Biodiversity conservation and the extinction of experience. Trends Ecol Evol 20:430-434

Millenium Ecosystem Assessment (MEA) (2005) Ecosystems and Human well-being. Island Press, Washington $\mathrm{DC}$

Moscovici S (2000) Social representations. Polity Press, Cambridge, Exploration in social psychology

Noss RF, Dobson AP, Baldwin R, Beier P, Davis CR, Dellasala DA, Francis J, Locke H, Nowak K, Lopez R, Reining C, Trombulak SC, Tabor G (2012) Bolder thinking for conservation. Conserv Biol 26:1-4

Novacek MJ (2008) Engaging the public in biodiversity issues. Proc Natl Acad Sci U S A 115(Suppl. 1):1157111578

Pickett STA, Cadenasso ML, Grove JM, Nilon CH, Pouyat RV, Zipperer WC, Costanza R (2001) Urban ecological systems: linking terrestrial ecological, physical and socioeconomic components of metropolitan areas. Annu Rev Ecol Syst 32:127-157

Pigliucci M (2012) Nonsense on stilts about science: field adventures of a scientist-philosopher. In: Goodwin J (ed). Ames, IA, Great Plains Society for the Study of Argumentation, pp. 19-28

Prévot-Julliard AC, Julliard R, Clayton S (2015) Historical evidence for nature disconnection in a 70-year time series of Disney animated films. Public Underst Sci 24:672-80

Pyle RM (2003) Nature matrix: reconnecting people with nature. Oryx 37:206-214

Raymond CM, Fazey I, Reed MS, Stringer LC, Robinson GM, Evely AC (2010) Integrating local and scientific knowledge for environmental management. J Environ Manag 91:1766-1777

Root-Bernstein M (2014) Nostalgia, the fleeting, and the rare in Chilean relationships to nature and nonhuman species. Soc Anim 22:560-579

Sezille C, Fournel A, Rouby C, Rinck F, Bensafi M (2014) Hedonic appreciation and verbal description of pleasant and unpleasant odors in untrained, trainee cooks, flavorists, and perfumers. Front Psychol 5:article 12

Shwartz A, Cosquer A, Jaillon A, Piron A, Julliard R, Raymond R, Simon L, Prévot-Julliard AC (2012) Urban biodiversity, city-dwellers and conservation: how does an outdoor activity day affect the human-nature relationship? PLoS One 7:e38642

Siebert R, Laschewski L, Dosch A (2008) Knowledge dynamics in valorising local nature. Sociol Rural 48:223-239

Snep RPH, Kooijmans JL, Kwak RGM, Foppen RPB, Parsons H, Awasthy M, Sierdsema HLK, Marzluff JM, Fernandez-Juricic E, de Laet J, van Heezik YM (2015) Urban bird conservation: presenting stakeholerspecific arguments for the development of bird-friendly cities. Urban Ecosyst. doi:10.1007/s11252-0150442-z

Soulé ME (1985) What is conservation biology? Bioscience 35:727-734

Thomas K (1983) Man and the natural world changing attitudes in England 1500-1800. Penguin Ltd, Harmondsworth, England

United-Nations (2011) World Urbanization Prospects. The 2011 Revision. United-Nations, New-York

Zia A, Todd AM (2010) Evaluating the effects of ideology on public understanding of climate change science: how to improve communication across ideological divides? Public Underst Sci 19:743-761 